\title{
Safety levels for organophosphate pesticide residues on fruits, vegetables, and nuts
}

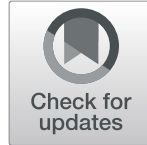

\author{
Elizabeth A. Jara and Carl K. Winter ${ }^{*}$ (D)
}

\begin{abstract}
A novel approach is developed to establish safety levels for organophosphate pesticides residues present in 80 fruit, vegetable, and nut commodities. These levels, known as Pesticide Safety Levels (PSL), represent the concentration of the organophosphate pesticide residue that would be required to cause daily exposure of the highest-consuming population subgroup at the 95th percentile of consumption (based upon US food consumption estimates) to reach the adjusted acute reference dose of the pesticide.

A total of 4,320 PSLs were developed for 54 organophosphate pesticides on the 80 commodities.

Comparisons of PSLS and tolerances and/or MRLs, when available, indicated that only a small percentage of

PSLs were lower than or equal to regulatory levels (1.9\% below/equal to tolerance levels and $2.3 \%$ below/ equal to Codex MRLs). In the pesticide/commodity combinations where PSLs were below tolerances and/or MRLs, monitoring results indicated that the maximum residues of organophosphate pesticides on the commodities were far below both the PSL and tolerance/MRL values.

In most cases, PSLs were much higher than existing tolerances and/or MRLs. PSLs were at least 100 times higher than tolerances in $50.1 \%$ of the comparisons and at least 100 times higher than MRLs $64.1 \%$ of the time. PSLs were at least ten times higher than tolerances $75.8 \%$ of the time and at least ten times higher than MRLs $82.8 \%$ of the time.

PSLs serve a useful role in determining the health significance, if any, in the event that residues of organophosphate pesticides exceed existing tolerances and/or MRLs as well as in cases where residues of organophosphate pesticides are detected on commodities for which no tolerance or MRL has been established. PSLs can also be used to customize pesticide residue monitoring programs to focus more on consumer safety than on good agricultural practices.
\end{abstract}

Keywords: Organophosphate pesticides, Residues, Tolerances, Maximum residue levels, Risk assessment

\section{Introduction}

The health significance of pesticide residues on foods exceeding standards such as US tolerances or Codex Maximum Residue Levels (MRLs) is poorly understood. While it may seem intuitive to consider the standards as safety standards, a deeper examination of the methods by which such levels are established indicates that tolerances and MRLs exist primarily as enforcement tools designed to determine if pesticide applications have been made according to directions rather than as safety standards (Winter 1992; Winter and Jara 2015). As such, pesticide residues that exceed tolerance or MRL levels or detections of pesticides on commodities for which

\footnotetext{
* Correspondence: ckwinter@ucdavis.edu

Department of Food Science and Technology, University of California Davis, One Shields Ave, Davis, CA 95616, USA
}

tolerances or MRLs do not exist may indicate pesticide misuse but rarely constitute safety concerns.

In an effort to illustrate the differences between pesticide tolerances/MRLs and levels of safety concern, Winter and Jara (2015) developed a novel method to identify acute and chronic Pesticide Food Safety Standard (PFSS) levels for the fungicide captan on strawberries. Regulatory limits for captan on strawberries ranged from 3 to $20 \mathrm{mg} / \mathrm{kg}$ (ppm) among various international jurisdictions. For chronic exposure to captan residues on strawberries, assuming average daily consumption of strawberries, it was determined that the PFSS level was $2000 \mathrm{ppm}$, meaning that consumers would have to eat strawberries containing $2000 \mathrm{ppm}$ of captan on a daily basis throughout their lifetimes to reach the chronic Reference Dose (RfD) for captan. In 
terms of acute exposure, it was determined that a single exposure to captan residue at $250 \mathrm{ppm}$ for the US population subgroup consuming the greatest amount of strawberries relative to body weight (in this case 2-5 year-olds) at the $95 \%$ percentile of exposure would allow exposure to reach the acute captan RfD. The acute PFSS for captan on strawberries was thus established to be $250 \mathrm{ppm}$, significantly exceeding captan MRLs and tolerance on strawberries of 3 to $20 \mathrm{ppm}$ (Winter and Jara 2015).

The captan example was fairly simple as estimates indicated that approximately $90 \%$ of captan exposure to US consumers resulted from strawberry consumption (Winter and Jara 2015). Accordingly, it was not necessary to consider how exposure contributions from captan residues on other commodities might influence determination of the PFSS for captan on strawberries.

In contrast with captan, which is used primarily on a single crop in the US and possesses relatively low acute toxicity with an acute RfD of $300 \mathrm{mg} / \mathrm{kg} /$ day (EU (European Union) 2019), the organophosphate (OP) pesticides are used broadly throughout the world in crop production and are much more acutely toxic. Many OPs possess acute RfDs at low $\mathrm{ug} / \mathrm{kg} /$ day levels and acute oral $\mathrm{LD}_{50}$ levels below $10 \mathrm{mg} / \mathrm{kg}$. Additionally, since all members of the OP family possess a similar mechanism of toxicological action (inhibition of acetylcholinesterase) the cumulative exposure to all members of the family needs to be considered in the risk assessment process and potentially in the establishment of pesticide safety levels.

Cumulative exposure assessments for OP residues found in several commonly consumed fruits and vegetables were recently performed (Jara and Winter, submitted for publication in Food and Chemical Toxicology, April 11, 2019). Results indicated that cumulative exposure to OPs from these foods resulted in exposures far below acute RfD levels at the 99.9th percentile of exposure for the general US population and for the highest exposed population subgroups (1-2 and 3-5 year-olds). Such results suggest that significant misuse of a single OP on a single commodity, resulting in very large residues, would be necessary for OP exposures to be of health concern and that subsequent exposure to typical levels of various OPs, found on various other commodities, would not contribute significantly to overall OP exposure in such a case. These findings therefore justify the establishment of pesticide safety levels for OPs on an individual OP/individual commodity basis and negate the need to consider influences from other OPs on other commodities.

This study calculates pesticide safety levels (PSLs) for 54 individual OPs on 80 fruits, vegetables, and nuts. Comparisons between PSLs and tolerances/ MRLs can demonstrate how regulatory levels relate to safety. In addition, comparing OP residue findings to PSLs in the event that tolerances or MRLs are exceeded or in cases where no tolerance or MRL was established for the OP detected provides an indication of the health significance, if any, of OP residues found to be in violation of regulatory limits.

\section{Methods}

\section{Food consumption estimates}

Consumption data were obtained from the U. S. What We Eat In America-Food Commodity Intake Database, 2005-2010 (WWEIA-FCID 2005-2010) developed by the US Environmental Protection Agency's Office of Pesticide Programs in collaboration with US Department of Agriculture. The FCID database translates food consumption as reported in WWEIA into consumption of US Environmental Protection Agency-defined food commodities. The main component of the FCID is the WWEIA data base which represents the integration of Continuing Survey of Food Intake by Individuals 1994-96/1998 (CSFII) with National Health and Nutrition Survey (NHANES). The current WWEIA-FCID is based on three cycles of data from the NHANES-WWEIA survey (2005-06, 2007-08, and 2009-10). The US Environmental Protection Agency has extracted some information from the NHANES/WWEIA survey for use in its WWEIAFCID database including demographic information, body weight, and food consumption data (FoodRisk.org 2000c, 2000d).

The FCID Consumption Calculator was used to extract the consumption data. The calculator is an application that provides distributions of food intake rates at different percentiles after the selection of specific age groups. First, an individual commodity is selected, and then specific populations subgroups are assigned (FoodRisk.org 2000b). In this research, the age subgroups used by the US Environmental Protection Agency in pesticide dietary exposure assessment were selected. A total of 8 age subgroup were incorporated into the intake calculator as well as the general population. Subgroups included those 0 to $<$ 12 months, 1 to $<3$ years, 3 to $<6$ years, 6 to $<13$ years, 13 to $<20$ years, 20 to $<50$ years, 50 years and older and females 13 to $<50$ years. One day consumption was selected and only eaters of the commodity were considered (FoodRisk.org 2000a). Tables generated by the intake calculator were used to select the population subgroup with the highest commodity consumption at 95th percentile. The consumption was expressed in $\mathrm{mg}$ of food consumed per $\mathrm{kg}$ of body weight per day. 


\section{Toxicity of OPs}

This study considered 54 individual OP pesticides. While considerable acute toxicological data exists for most of the OPs, the various studies used to estimate toxicity for specific OPs span several decades and include a wide variety of different toxicological endpoints measured, including No Observable Adverse Effect Levels, Low Observable Adverse Effect Levels, and Benchmark Doses, and studies of different dosing regimens among different animal strains and species. Some studies measure plasma acetylcholinesterase inhibition while others measure brain acetylcholinesterase inhibition. In addition, the US Environmental Protection Agency may assign different uncertainty factors among different OPs to determine adjusted acute RfD levels (EPA (Environmental Protection Agency) 2006b).

Jara and Winter (submitted for publication in Food and Chemical Toxicology, April 11, 2019) developed a novel method to assess cumulative dietary exposure to OPs using acute $\mathrm{LD}_{50}$ levels to standardize the toxicity among OPs. Benefits of this approach are that the same toxicological endpoint (death) is studied for all of the OPs and that $\mathrm{LD}_{50}$ data are relatively accessible. A comparison of findings between the LD50 method to assess relative potencies of OPs with methods using Benchmark Doses and No Observable Adverse Effect Levels indicated some differences among the three methods but all methods yielded comparable findings demonstrating that acute cumulative OP exposure was typically well below levels of toxicological concern for all population subgroups studied.

In this study, acute oral $\mathrm{LD}_{50}$ values for OPs were acquired from the toxicological literature and values selected for each specific OP represented the lowest reported $\mathrm{LD}_{50}$ value for female rats. The decision to select findings from female rat studies was arbitrary but provided consistency regarding relative potencies of the various OPs. In cases where female rat $\mathrm{LD}_{50}$ values were not specified, data for generic rats were used. An index OP, disulfoton, was selected based on the quality of acute toxicological data and a relatively small difference between the No Observed Adverse Effect Level and the Lowest Observed Adverse Effect Level (EPA (Environmental Protection Agency) 2006j). Relative Potency Factors (RPFs) were expressed for each of the OPs by dividing the $\mathrm{LD}_{50}$ of disulfoton with the $\mathrm{LD}_{50}$ of the specific OPs. A list of $\mathrm{LD}_{50}$ values and RPFs is provided in Table 1.

\section{Calculation of PSLs}

PSLs were calculated to represent the concentration of the pesticide residue in $\mathrm{ppm}(\mathrm{mg} / \mathrm{kg})$ that would be required for daily exposure to the OP reach the adjusted acute RfD of the OP when food was consumed by a member of the population subgroup with the highest consumption at the 95th percentile of consumption for the subgroup. The adjusted acute RfD was calculated by dividing the acute RfD of disulfoton by the RPF for the specific OP. The acute RfD for disulfoton was considered to be $0.0025 \mathrm{mg} / \mathrm{kg} /$ day, based on an acute No Observable Adverse Effect Level of $0.25 \mathrm{mg} / \mathrm{kg} /$ day and the typical 100-fold uncertainty factor applied in the RfD calculation (EPA (Environmental Protection Agency) 2006j). This approach provides a margin of exposure (MOE) of 100 relative to the No Observable Adverse Effect Level.

Exposure can be calculated by multiplying the concentration of the residue on the food $(\mathrm{mg} / \mathrm{kg})$ by the consumption level (best considered as $\mathrm{kg}$ of food consumed per kg of body weight per day). By setting exposure to represent the adjusted acute RfD for an OP, the PSL can be calculated by the following equation:

$\mathrm{PSL}(\mathrm{mg} / \mathrm{kg})=($ disulfoton acute RfD, $0.0025 \mathrm{mg} / \mathrm{kg} / \mathrm{day} \div \mathrm{RPF})$

/food consumption ( $\mathrm{kg}$ food per kg body weight per day).

As an example, consider the calculation for the PSL for chlorpyrifos on apples. The RPF (see Table 1) for chlorpyrifos is 0.0085 and consumption at the 95th percentile for the most exposed population subgroup ( 0 to $<12$ months) is $18.2 \mathrm{~g}$ of apples per $\mathrm{kg}$ body weight per day $(0.0182 \mathrm{~kg}$ apples per $\mathrm{kg}$ body weight per day). Substituting the values allows calculation of the chlorpyrifos PSL:

PSL $($ chlorpyrifos, apples $)=(0.0025 \mathrm{mg} / \mathrm{kg} /$ day $\div 0.0085)$

$/ 0.0182 \mathrm{~kg}$ food per $\mathrm{kg}$ body weight per day $=16 \mathrm{mg} / \mathrm{kg}(\mathrm{ppm})$.

This level is far greater than the tolerance and Codex MRL for chlorpyrifos which are 0.01 and $1 \mathrm{ppm}$, respectively. This finding indicates that residue levels for chlorpyrifos on apples must be significantly higher than the legal limits before such residues would be of acute health concern to consumers.

\section{Results and discussion}

A complete list of PSLs for 54 OPs on 80 fruit, vegetable, and nut commodities is provided in Additional file 1: Table S1. The table is organized by commodity and sorted alphabetically. Specific OPs listed for each commodity are also sorted alphabetically.

While only a small number of specific OPs have tolerances and/or Codex MRLs established for specific commodities, comparing PSLs with the established tolerances/MRLs provides an indication of the differences between PSLs and regulatory limits for pesticide residues. An additional value of Additional file 1: Table 
Table $1 L D_{50}$ values and RPFs for organophosphate pesticides

\begin{tabular}{|c|c|c|c|}
\hline $\mathrm{OP}$ & LD50 (mg/kg) & RPF & Reference \\
\hline acephate & 1000 & 0.0019 & EPA, 2006c \\
\hline azinphos-methyl & 4.4 & 0.4318 & EPA, 2006d \\
\hline bensulide & 1082 & 0.0018 & EPA, 2006e \\
\hline cadusafos & 391 & 0.0049 & Meister and Sine, 2012 \\
\hline carbophenothion & 10 & 0.1900 & TAH, 1994 \\
\hline carbophenothion-methyl & 48 & 0.0396 & USDA, 1966 \\
\hline chlorfenvinophos & 9.8 & 0.1939 & Ambrose 1970 \\
\hline chlorpyrifos & 223 & 0.0085 & EPA, $2006 f$ \\
\hline coumaphos & 17 & 0.1118 & EPA, 1996 \\
\hline crotoxyphos & 52.8 & 0.0360 & Worthing 1983 \\
\hline demeton & 2.5 & 0.7600 & Gaines, 1960 \\
\hline dialifos & 5 & 0.3800 & Pearce, 1978 \\
\hline diazinon & 1160 & 0.0016 & EPA, $2006 \mathrm{~g}$ \\
\hline dichlorvos & 56 & 0.0339 & EPA, 2006h \\
\hline dicrotophos & 8 & 0.2375 & EPA, 2006i \\
\hline dimethoate & 414 & 0.0046 & EPA, 2008 \\
\hline dioxathion & 43 & 0.0442 & Worthing 1983 \\
\hline disulfoton & 1.9 & 1.0000 & EPA, 2006j \\
\hline EPN & 7 & 0.2714 & Lewis, 1996 \\
\hline ethion & 208 & 0.0091 & Tomlin, 1994 \\
\hline ethoprop & 32.8 & 0.0579 & EPA, 2006k \\
\hline fenamiphos & 3 & 0.6333 & EPA, 2002 \\
\hline fenchlorphos & 1250 & 0.0015 & Matsumura 1985 \\
\hline fenitrothion & 1720 & 0.0011 & Tomlin 1994 \\
\hline fensulfothion & 1.8 & 1.0556 & ACGIH, 1991 \\
\hline fenthion & 461 & 0.0041 & EPA, 2001 \\
\hline fonofos & 8 & 0.2375 & Hartley and Kidd, 1987 \\
\hline isocarbophos & 50 & 0.0380 & Eto, 1974 \\
\hline isofenphos & 28 & 0.0679 & Lewis, 1996 \\
\hline malathion & 5700 & 0.0003 & EPA, 2009 \\
\hline methamidophos & 13 & 0.1462 & EPA, 2006l \\
\hline methidathion & 32 & 0.0594 & O’Neil, 2006 \\
\hline mevinphos & 2.2 & 0.8636 & CDPR, 1994 \\
\hline monocrotophos & 14 & 0.1357 & FAO/UNEP, 1997 \\
\hline naled & 85 & 0.0224 & CDPR, 1999 \\
\hline omethoate & 25 & 0.0760 & JMPR, 1996 \\
\hline oxydemeton-methyl & 48 & 0.0396 & EPA, $2006 \mathrm{~m}$ \\
\hline parathion & 2 & 0.9500 & Lewis 1996 \\
\hline parathion-methyl & 24 & 0.0792 & Worthing and Walker, 1987 \\
\hline phorate & 1.4 & 1.3571 & EPA, 2006n \\
\hline phosalone & 90 & 0.0211 & EPA, 1987 \\
\hline phosmet & 113 & 0.0168 & EPA, 20060 \\
\hline phosphamidon & 17.4 & 0.1092 & Worthing and Walker, 1987 \\
\hline phoxim & 1400 & 0.0014 & IPCS, 2000 \\
\hline
\end{tabular}


Table $1 \mathrm{LD}_{50}$ values and RPFs for organophosphate pesticides (Continued)

\begin{tabular}{llll}
\hline OP & LD50 $(\mathrm{mg} / \mathrm{kg})$ & RPF & Reference \\
\hline pirimiphos-methyl & 2400 & 0.0008 & EPA, 2006p \\
profenofos & 400 & 0.0048 & Lewis, 1996 \\
propetamphos & 96.4 & 0.0197 & EPA, 2006a \\
prothiophos & 1800 & 0.0011 & Bayer, 2008 \\
quinalphos & 26 & 0.0731 & USDA, 1966 \\
sulprofos & 176 & 0.0108 & Tomlin, 2002 \\
terbufos & 1.5 & 1.2667 & EPA, 2006q \\
tetrachlorvinphos & 465 & 0.0041 & EPA, 1995 \\
triazophos & 82 & 0.0232 & JMPR, 2002 \\
trichlorfon & 136 & 0.0140 & EPA, 1997 \\
\hline
\end{tabular}

S1 is that it allows determination of the potential health significance of OP residues detected on commodities for which tolerances and/or Codex MRLs have been established; in cases where residue levels are below the PSLs, the potential health significance is considered to be negligible.

Table 2 provides a comparison between PSLs and tolerances. A total of 359 OP tolerances were established on the 80 commodities. In seven OP/commodity combinations $(1.9 \%)$, the PSLs were equal to or lower than the tolerances, indicating that residues at the tolerance level would provide an exposure of potential health concern if the food were eaten at the upper 95th percentile consumption rate for the highest-consuming population subgroup. Tolerances were at least 10 times lower than the PSLs in $75.8 \%$ of the OP/commodity combinations and at least 100 times lower than the PSLs in $50.1 \%$ of the $\mathrm{OP} /$ commodity combinations.

Table 3 provides a comparison between PSLs and Codex MRLs. A total of 128 OP MRLs were established on the 80 commodities. In three OP/commodity combinations $(2.3 \%)$ the PSLs were equal to or lower than the MRLs, including two combinations where the tolerance was also lower than the PSL. MRLs were at least 10 times lower than the PSLs in $82.8 \%$ of the OP/commodity combinations and at least 100 times lower than the PSLs in $64.1 \%$ of the OP/commodity combinations.

Table 4 lists the OP/commodity combinations where tolerances and/or Codex MRLs were greater than the
PSLs. The eight combinations involved three OPs: phosmet (four instances), omethoate (three instances) and phorate (one instance).

Findings from monitoring programs, when available, do not indicate that residues from these OPs on these commodities do not commonly approach PSLs, tolerances, or Codex MRLs. The US Department of Agriculture's Pesticide Data Program (PDP) analyzed 2160 apple samples for phosmet from 2010 to 2017. Residues were detected in $6.7 \%$ of the samples, and the maximum residue detected was $0.49 \mathrm{ppm}$, representing only $6 \%$ of the PSL (PDP (Pesticide Data Program) 2015a, 2015b, 2015c; PDP (Pesticide Data Program) 2016a, 2016b; PDP (Pesticide Data Program) 2017, PDP (Pesticide Data Program) 2018a, 2018b). The maximum phosmet residue on apples analyzed by the California Department of Pesticide Regulation (CDPR) from 2016 to 2017 was $0.67 \mathrm{ppm}$ (CDPR (California Department of Pesticide Regulation) 2016, 2017). Kiwifruit was not monitored by PDP but the CDPR monitoring program analyzed 36 kiwifruit samples but did not detect phosmet residues in any of the samples (CDPR (California Department of Pesticide Regulation) 2016, 2017). PDP analyzed 1786 samples of sweet potato during 2010-2017 resulting in a phosmet detection rate of $0.8 \%$ with the maximum phosmet residue detected at $0.41 \mathrm{ppm}$, representing 3.4\% of the PSL. During 2016 to 2017 CDPR analyzed 127 samples of sweet potatoes for phosmet

Table 2 Ratio of pesticide safety level to tolerance for OP/commodity combinations

\begin{tabular}{|c|c|c|c|c|c|c|c|}
\hline & $\leq 1$ & $>1$ to 5 & $>5$ to 10 & $>10$ to 100 & $>100$ to 1000 & $>1000$ to 5000 & $>5000$ \\
\hline Number of combinations & 7 & 35 & 25 & 92 & 122 & 53 & 25 \\
\hline Percentage of combinations & 1.9 & 9.7 & 7.0 & 25.6 & 34.0 & 14.7 & 7 \\
\hline
\end{tabular}


Table 3 Ratio of pesticide safety level to MRL for OP/commodity combinations

\begin{tabular}{llllllll}
\hline & $\leq 1$ & $>1$ to 5 & $>5$ to 10 & $>10$ to 100 & $>100$ to 1000 & $>1000$ to 5000 & $>5000$ \\
\hline Number of combinations & 3 & 11 & 8 & 24 & 41 & 32 & 25 \\
Percentage of combinations & 2.3 & 8.6 & 6.3 & 18.8 & 19.5 & 16.5
\end{tabular}

but no residues were detected (CDPR (California Department of Pesticide Regulation) 2016, 2017).

A total of 2159 orange samples were analyzed by PDP from 2010 to 2017 for omethoate residues but no residues were detected (PDP (Pesticide Data Program) 2015a, 2015b, 2015c PDP (Pesticide Data Program) 2016a, 2016b; PDP (Pesticide Data Program) 2017, PDP (Pesticide Data Program) 2018a, 2018b). Of the 1426 tangerine samples analyzed by PDP, only two demonstrated detectable residues with a maximum detected residue of $0.025 \mathrm{ppm}$ (well below the PSL of $1.9 \mathrm{ppm}$ ) (PDP (Pesticide Data Program) 2015a, 2015b, 2015c; PDP (Pesticide Data Program) 2016a, 2016b; PDP (Pesticide Data Program) 2017, PDP (Pesticide Data Program) 2018a, 2018b). A total of 9 watermelon samples (less than $1 \%$ ) of 1131 analyzed by PDP for residues of omethoate were positive with the maximum residue of $0.024 \mathrm{ppm}$ far below the PSL of $0.6 \mathrm{ppm}$ (PDP (Pesticide Data Program) 2015a, 2015b, 2015c; PDP (Pesticide Data Program) 2016a, 2016b; PDP (Pesticide Data Program) 2017, PDP (Pesticide Data Program) 2018a, 2018b).

No phorate residues were detected in any of the 1415 samples of potatoes analyzed by PDP from 2010 to 2017 (PDP (Pesticide Data Program) 2015a, 2015b, 2015c; PDP (Pesticide Data Program) 2016a, 2016b; PDP (Pesticide Data Program) 2017, PDP (Pesticide Data Program) 2018a, 2018b).

\section{Conclusions}

Pesticide Safety Levels for OPs in fruits, vegetables, and nuts provide valuable information that helps elucidate acute dietary risks from pesticide residues. In contrast with regulatory limits such as pesticide tolerances and Codex MRLs that are established primarily on the basis of good agricultural practices (Winter 1992), PSLs are set on the basis of safety and allow a rapid determination of the potential health significance from specific residue findings. They are useful in cases where specific violative residues exceed established tolerances and/or MRLs as well as in cases where residues of an OP are detected on a commodity for which no tolerance or MRL has been established; comparison of the residue level detected with the PSL provides an indication of the health significance, if any, of the detected residue.

Comparisons of PSLs with tolerances and MRLs demonstrate that tolerances and MRLs clearly do not represent levels of safety concern, and that pesticide residue violations are rarely of health consequence, confirming previous work (Winter 1992; Winter and Jara 2015). This work demonstrates that the majority of OP tolerances and MRLs on the 80 commodities considered were at least 100 times lower than PSLs.

In only a small number of cases were the PSLs lower than or equal to the tolerance or MRL levels, and monitoring results examining these specific OP/ commodity combinations, when available, indicated that detected residues of the OPs were far below PSL, tolerance, and MRL values. Nevertheless, if pesticide residue monitoring programs are designed to focus on food safety rather than on good manufacturing practices, it would be prudent to develop sampling approaches that preferentially target OP/commodity combinations where the PSLs are below, equal to, or slightly above tolerances and/or MRLs.

The PSLs developed in this study are based upon food consumption practices in the US. This approach could easily be adapted to the determination of PSLs in other parts of the world where food consumption

Table 4 OP/commodity combinations where tolerances and/or MRLs are equal to or exceed PSLs

\begin{tabular}{lllll}
\hline Pesticide & Commodity & PSL (ppm) & Tolerance (ppm) & Codex MRL (ppm) \\
\hline Phosmet & Apple & 8.2 & 10 & 10 \\
Phosmet & Apricot & 8.1 & NE & 10 \\
Phosmet & Kiwifruit & 19 & 25 & $\mathrm{NE}$ \\
Phosmet & Sweet potato & 12 & 12 & $\mathrm{NE}$ \\
Omethoate & Orange & 2 & 2 & $\mathrm{NE}$ \\
Omethoate & Tangerine & 1.9 & 2 & $\mathrm{NE}$ \\
Omethoate & Watermelon & 0.6 & 1 & $\mathrm{NE}$ \\
Phorate & Potato & 0.15 & 0.2 & 0.3 \\
\hline
\end{tabular}


patterns may be different provided that food consumption data are available.

\section{Additional file}

Additional file 1 Table S1: Organophosphate (OP) Pesticide Safety Levels (PSLs) for 80 fruit, vegetable, and nut commodities (DOCX 806 kb)

\section{Abbreviations}

CDPR: California Department of Pesticide Regulations; MRL: Maximum Residue Level; OP: Organophosphate; PDP: Pesticide Data Program; PFSS: Pesticide Food Safety Standard; PSL: Pesticide Safety Level; RfD: Reference dose; RPF: Relative Potency Factor

\section{Acknowledgements}

N/A

\section{Authors' contributions}

EAJ was responsible for data collection and calculation of Pesticide Safety Levels. CKW assisted with the design of the study and with preparation of the manuscript. Both authors read and approved the final manuscript.

\section{Authors' information}

N/A

\section{Funding}

The project received no external funding. The authors thank the Chilean Government and the National Commission for Scientific and Technological Research (CONICYT) for providing support for author EAJ's graduate studies through the Becas Chile Scholarships.

\section{Availability of data and materials}

All data used in this study was acquired from publicly available sources and such sources are referenced in the manuscript. The formula used to calculate Pesticide Safety Levels from the aforementioned data is presented in the manuscript.

\section{Competing interests}

The authors declare that they have no competing interests.

Received: 2 May 2019 Accepted: 11 July 2019

Published online: 10 August 2019

\section{References}

ACGIH (American Conference of Governmental Industrial Hygienists) Documentation of the threshold limit value and biological exposures indices. $6^{\text {th }}$ ed. volumes I, II, III. American Conference of Governmental Industrial Hygienists, Cincinnati; 1991.

Ambrose AM, Larson PS, Borzelleca JF, Hennigar GR. Toxicologic studies on diethyl-1-(2,4-dichlorophenyl)-2-chlorovinyl phosphate. Food Chem Toxicol. 1970;17(2):323-36. https://doi.org/10.1016/0041-008X(70)90189-4.

Bayer 2008. Material safety data sheet. Tokuthion. Accessed 23 Apr 2019 http:// www.lidorr.com/_uploads/dbsattachedfiles/msdstokuthion.pdf

CDPR (California Department of Pesticide Regulation) 1994. Mevinphos (phosdrin) risk characterization. https:/oehha.ca.gov/media/downloads/pesticides/ report/mevinphosrcdmemooehha1994 1.pdf. Accessed 6 Aug 2019.

CDPR (California Department of Pesticide Regulation) 1999. Naled-risk characterization document. Sacramento: California Department of Pesticide Regulation

CDPR (California Department of Pesticide Regulation) 2016 Annual residue data https://www.cdpr.ca.gov/docs/enforce/residue/rsmonmnu.htm

CDPR (California Department of Pesticide Regulation) 2017 Annual residue data. https://www.cdpr.ca.gov/docs/enforce/residue/rsmonmnu.htm

EPA (Environmental Protection Agency). Pesticide fact sheet number 148 Washington, DC: Office of Pesticide Programs, Registration Division; 1987.

EPA (Environmental Protection Agency). Reregistration decision for Tetrachlorvinphos: Office of Pesticide Programs: 1995. Accessed 23 Apr 2019 https://archive.epa.gov/pesticides/reregistration/web/pdf/0321red.pdf
EPA (Environmental Protection Agency) 1996. Reregistration eligibility decision facts. Coumaphos. Accessed 24 Apr 2019 https://archive.epa.gov/pesticides/ reregistration/web/pdf/0018fact.pdf.

EPA (Environmental Protection Agency). Reregistration decision for Trichlorfon: Office of Pesticide Programs; 1997. Accessed 23 Apr 2019 https://archive.epa. gov/pesticides/reregistration/web/pdf/0104.pdf

EPA (Environmental Protection Agency). Interim reregistration decision for Fenthion: Office of Pesticide Programs; 2001. Accessed 23 Apr 2019 https:// archive.epa.gov/pesticides/reregistration/web/pdf/0290ired.pdf

EPA (Environmental Protection Agency). Interim reregistration decision for Fenamiphos: Office of Pesticide Programs; 2002. Accessed 23 Apr 2019 https:// archive.epa.gov/pesticides/reregistration/web/pdf/fenamiphos_ired.pdf

EPA (Environmental Protection Agency). Interim reregistration decision for Propetamphos: Office of Pesticide Programs; 2006a. Accessed 23 Apr 2019. https://www3.epa.gov/pesticides/chem search/reg_actions/reregistration/ ired_PC-113601_1-Dec-00.pdf

EPA (Environmental Protection Agency) 2006b. Organophosphorus cumulative risk assessment 2006 update. Accessed 28 Mar 2019 https://www.regulations. gov/document?D=EPA-HQ-OPP-2006-0618-0002.

EPA (Environmental Protection Agency). Reregistration decision for Acephate: Office of Pesticide Programs; 2006c. Accessed 28 Mar 2019 https://archive. epa.gov/pesticides/reregistration/web/pdf/acephate_red.pdf

EPA (Environmental Protection Agency). Reregistration decision for Azinphos methyl: Office of Pesticide Programs; 2006d. https://archive.epa.gov/ pesticides/reregistration/web/pdf/azm_red.pdf

EPA (Environmental Protection Agency). Reregistration decision for Bensulide: Office of Pesticide Programs; 2006e. Accessed 28 Mar 2019 https://archive. epa.gov/pesticides/reregistration/web/pdf/bensulide_red.pdf

EPA (Environmental Protection Agency). Reregistration eligibility decision for Chlorpyrifos: Office of Pesticide Programs; 2006f. https://www3.epa.gov/ pesticides/chem_search/reg_actions/reregistration/ired_PC-059101_28Sep-01.pdf

EPA (Environmental Protection Agency). Reregistration decision for Diazinon: Office of Pesticide Programs; 2006g. Accessed 28 Mar 2019 https://archive. epa.gov/pesticides/reregistration/web/pdf/diazinon_red.pdf

EPA (Environmental Protection Agency). Reregistration decision for Dichlorvos: Office of Pesticide Programs; 2006h. Accessed 28 Mar 2019 https://archive. epa.gov/pesticides/reregistration/web/pdf/ddvp_ired.pdf

EPA (Environmental Protection Agency). Reregistration decision for Dicrotophos: Office of Pesticide Programs; 2006i. Accessed 23 Apr 2019 https://archive.epa. gov/pesticides/reregistration/web/pdf/dicrotophos_red.pdf

EPA (Environmental Protection Agency). Reregistration decision for Disulfoton: Office of Pesticide Programs; 2006j. Accessed 28 Mar 2019 https://archive. epa.gov/pesticides/reregistration/web/pdf/disulfoton_red.pdf

EPA (Environmental Protection Agency). Reregistration decision for Ethoprop: Office of Pesticide Programs; 2006k. Accessed 28 Mar 2019 https://archive. epa.gov/pesticides/reregistration/web/pdf/ethoprop red.pdf

EPA (Environmental Protection Agency). Reregistration decision for Methamidophos: Office of Pesticide Programs; 2006l. Accessed $28 \mathrm{Mar}$ 2019 https://archive.epa.gov/pesticides/reregistration/web/pdf/ methamidophos red.pdf

EPA (Environmental Protection Agency). Reregistration decision for Oxydemethon methyl: Office of Pesticide Programs; 2006m. Accessed 28 Mar 2019 https://archive.epa.gov/pesticides/reregistration/web/pdf/ odm_red.pdf

EPA (Environmental Protection Agency). Reregistration decision for Phorate: Office of Pesticide Programs; 2006n. Accessed 23 Apr 2019 https://archive. epa.gov/pesticides/reregistration/web/pdf/phorate_red.pdf

EPA (Environmental Protection Agency). Reregistration decision for Phosmet: Office of Pesticide Programs; 2006o. Accessed 03/28/2019 https://archive.epa. gov/pesticides/reregistration/web/pdf/phosmet_red.pdf

EPA (Environmental Protection Agency). Reregistration decision for Pirimiphos-methyl: Office of Pesticide Programs; 2006p. Accessed $23 \mathrm{Apr}$ 2019. https://archive.epa.gov/pesticides/reregistration/web/pdf/ pirimiphos_methyl_red.pd

EPA (Environmental Protection Agency). Reregistration decision for Terbufos: Office of Pesticide Programs; 2006q. Accessed 23 Apr 2019. https://archive. epa.gov/pesticides/reregistration/web/pdf/terbufos_red.pdf

EPA (Environmental Protection Agency). In: Office of Pesticide Programs, editor. Interim Reregistration decision for Dimethoate; 2008. https://archive.epa.gov/ pesticides/reregistration/web/pdf/dimethoate_ired_revised.pdf. 
EPA (Environmental Protection Agency). Reregistration decision for Malathion: Office of Pesticide Programs; 2009. Accessed 28 Mar 2019 https://archive.epa.gov/pesticides/reregistration/web/pdf/malathionred-revised.pdf

Eto M. Organophosphorus pesticides: organic and biological chemistry. Cleveland: CRC Press, Inc; 1974.

EU (European Union) 2019. EU Pesticides database: Captan. Accessed 29 Apr 2019 http://ec.europa.eu/food/plant/pesticides/eu-pesticides-database/ public/?event=activesubstance.detail\&language $=$ EN\&selectedID $=1078$

FAO/UNEP (Food Agricultural Organization of United Nations/United Nations Environmental Program for the operation of prior informed consent), 1997. Decision guidance document for methamidophos, methyl parathion monocrotophos, parathion and phosphamidon. Accessed 29 Mar 2019 http://www.fao.org/3/w5715e/w5715e00.htm\#Contents

FoodRisk.org (2000a) Commodity consumption calculator. Accessed 24 Apr 2019. http://fcid.foodrisk.org/percentiles.

FoodRisk.org (2000b) Consumption calculator getting started guide. Accessed 24 Apr 2019. http://fcid.foodrisk.org/docs/Getting_Started_8-25-17.pdf.

FoodRisk.org (2000c) U. S. What We Eat In America-food commodity intake database, 2005-2010 (WWEIA-FCID 2005-2010). Accessed 24 Apr 2019. http:// fcid.foodrisk.org.

FoodRisk.org (2000d) 2005-2010 What We Eat In America - food commodity intake database (WWEIA-FCID 0510) Accessed 24 Apr 2019 http://fcid foodrisk.org/docs/WWEIA-FCID_0510_Background-Codebooks-ControlStats. pdf

Gaines TB. The acute toxicity of pesticides to rats. Toxicol Appl Pharmacol. 1960; 2(1):88-99. https://doi.org/10.1016/0041-008X(60)90074-0.

Hartley D, Kidd H, editors. The agrochemicals handbook. 2nd ed. Herts: The Royal Society of Chemistry; 1987.

IPCS (International program on Chemical Safety) 2000. World Health Organization, toxicological evaluation of certain veterinary drugs residues in food. Food Additive series 43 - Insecticide Phoxim. Accessed 04/23/2019. http://www.inchem.org/documents/jecfa/jecmono/v43jec04.htm

JMPR (Joint Meeting of the FAO/WHO Panel of Experts on Pesticide Residues) 1996. Pesticide residues in food. Dimethoate, Omethoate and Formothion. Accessed 29 Mar 2019. http://www.fao.org/3/W3727E/w3727e00. htm\#Contents

JMPR (Joint Meeting of the FAO/WHO Panel of Experts on Pesticide Residues) 2002. Pesticides residues in food 2002 - triazophos. Accessed 23 Apr 2019. http://www.inchem.org/documents/jmpr/jmpmono/2002pr14.htm

Lewis RJ. Sax's dangerous properties of industrial materials. 9th ed. Volumes 1-3. New York: Van Nostrand Reinhold; 1996.

Matsumura F. Toxicology of insecticides. 2nd ed. New York: Plenum Press; 1985

Meister RT, Sine C. Crop protection handbook. 98th ed. Willoughby: Meister Media Worldwide; 2012

O'Neil MJ, editor. The Merck index-an encyclopedia of chemicals, drugs and biologicals. Whitehouse Station: Merck and Co., Inc; 2006.

PDP (Pesticide Data Program) 2015a. Annual report 2010. USDA Agricultural Marketing Service. Accessed 24 Apr 2019. https://www.ams.usda.gov/ datasets/pdp/pdpdata

PDP (Pesticide Data Program) 2015b. Annual report 2011. USDA Agricultura Marketing Service. Accessed 24 Apr 2019. https://www.ams.usda.gov/ datasets/pdp/pdpdata

PDP (Pesticide Data Program) 2015c. Annual report 2013. USDA Agricultural Marketing Service. Accessed 24 Apr 2019. https://www.ams.usda.gov/ datasets/pdp/pdpdata

PDP (Pesticide Data Program) 2016a. Annual report 2012. USDA Agricultural Marketing Service. Accessed 24 Apr 2019. https://www.ams.usda.gov/ datasets/pdp/pdpdata

PDP (Pesticide Data Program) 2016b. Annual report 2014. USDA Agricultural Marketing Service. Accessed 24 Apr 2019. https://www.ams.usda.gov/ datasets/pdp/pdpdata

PDP (Pesticide Data Program) 2017. Annual report 2015. USDA Agricultural Marketing Service. Accessed 24 Apr 2019. https://www.ams.usda.gov/ datasets/pdp/pdpdata

PDP (Pesticide Data Program) 2018a. Annual report 2016. USDA Agricultural Marketing Service. Accessed 24 Apr 2019. https://www.ams.usda.gov/ datasets/pdp/pdpdata

PDP (Pesticide Data Program) 2018b. Annual report 2017. USDA Agricultural Marketing Service. Accessed 24 Apr 2019. https://www.ams.usda.gov/ datasets/pdp/pdpdata
Pearce EM. Kirk-Othmer encyclopedia of chemical technology. $3^{\text {rd }}$ ed., Volumes 126. New York: Wiley; 1978.

TAH (The Agrochemicals Handbook). $3^{\text {rd }}$ ed. Royal Society of Chemistry information systems. Surrey: Unwin Brothers Ltd; 1994.

Tomlin CDS, editor. The pesticide manual: a world compendium. 10th ed. Surrey: The British Crop Protection Council; 1994.

Tomlin CDS, editor. Sulprofos (35400-43-2). The e-pesticide manual, version 2.2. Surrey: The British Crop Protection Council; 2002.

USDA (U. S. Department of Agriculture) 1966. Agricultural Research Service, USDA Information Memorandum, 20(10).

Winter CK. Pesticide tolerances and their relevance as safety standards. Reg Toxicol Pharmacol. 1992;15:137-50 Accessed 25 Apr 2019. https://doi.org/1 0.1016/0273-2300(92)90045-B

Winter CK, Jara EA. Pesticide food safety standards as companions to tolerances and maximum residue limits. J Integrative Agriculture. 2015;14:2358-64. https://doi.org/10.1016/S2095-3119(15)61117-0.

Worthing CR, editor. The pesticide manual: a world compendium. 7th ed. Croydon: The British Crop Protection Council; 1983.

Worthing CR, Walker SB, editors. The pesticide manual- a world compendium. $8^{\text {th }}$ ed. Thornton Heath: The British Crop Protection Council; 1987.

\section{Publisher's Note}

Springer Nature remains neutral with regard to jurisdictional claims in published maps and institutional affiliations.
Ready to submit your research? Choose BMC and benefit from:

- fast, convenient online submission

- thorough peer review by experienced researchers in your field

- rapid publication on acceptance

- support for research data, including large and complex data types

- gold Open Access which fosters wider collaboration and increased citations

- maximum visibility for your research: over $100 \mathrm{M}$ website views per year

At BMC, research is always in progress.

Learn more biomedcentral.com/submissions 